\title{
Impact Of Balanced Scorecard Implementation On Financial And Non-Financial Aspects In Private Hospital: A Literature Review
}

\author{
Sri Pramesthi Wisnu Bowo Negoro ${ }^{\text {a }}$, Winny Setyonugroho ${ }^{\text {* }}$ \\ a wisnu.developer@gmail.com \\ ${ }^{a}$ Master of Hospital Administration, Universitas Muhammadiyah Yogyakarta
}

\begin{abstract}
Background: Hospital progress in a health system is essential to achieve the goal of health services, i.e., access to comprehensive health for all people. Hospitals play a pivotal role in achieving the goal. One of the issues preventing hospitals from making satisfactory development in terms of performance and productivity includes the difficulty in measuring the services provided. Therefore, the Balanced Scorecard (BSC) was created to overcome this problem.

Objective: This study aims to determine the impact of implementing the Balanced Scorecard (BSC) on financial and non-financial aspects in private hospitals.

Research Method: The researcher employed a systematic search strategy to identify the keywords "Balanced Scorecard" AND "Hospital" in 5 databases (Pubmed, Taylor\&Francis Online, Wiley, Springer, and Emerald). The five databases were screened from the title, the essence, to the entire paper. The researcher also examined whether the journals were Scopus-indexed or not. Furthermore, there were three journals being reviewed.

Results: After conducting a screening process, a total of 2,396 journals were found, and only three academic papers matched the inclusion and exclusion criteria of this study. Those journals were from Ohio Summa Hospital, Barberton Citizen Hospital, and several private hospitals in Taiwan. The journals investigated the impact of implementing the BSC on financial and non-financial aspects.

Conclusion: The three journals demonstrate that the implementation of BSC in hospitals can improve hospital performance in terms of financial and non-financial aspects. The BSC implementation in hospitals could provide clear direction in determining policies, managing resources and routine activities, and building systems in each hospital unit.
\end{abstract}

Keywords: Balanced Scorecard ; Private Hospital ; Implementation

\section{Introduction}

A health system is designed to achieve comprehensive health access to all communities, responsive services, and equitable financing for both service providers and health care recipients. Among others, hospitals play a pivotal role in achieving these goals. Public and private hospitals face challenges in providing quality services, reducing costs, and having higher efficiency to increase patient satisfaction and attain the main goal 
of the health system[1]. In addition, every hospital, especially private hospitals established without government support, expects to provide financial and service quality well. They require a sound performance management strategy to grow and develop[2]. For this purpose, health care facilities are required to provide efficient and high-quality, affordable, and integrated services.

Culture, organisation, and managerial practices become key issues that hinder hospitals from developing satisfactory system performance and productivity. This is inconsistent with a competitive business since operating practices are not driven by cost or sound finance. Several specific reasons why hospitals have not been active or successful in this field are, among others, because hospital staff have insufficient experience in a competitive environment, staff participation is less, especially among doctors, and the services provided are hard to measure. Thus, several performance analysis tools were created to address these problems.

The Balanced Scorecard (BSC) is one of the methods applied as a measurement tool for performance management in various fields, particularly hospitals. BSC technique is widely utilised to measure the performance of an organisation in accordance with its vision and strategy, which serves as the basis of four BSC perspectives, i.e., analysing the financial sector by considering customer preferences, internal processes consisting of effectiveness and efficiency, as well as learning and growth. In addition to the performance measurement and evaluation tool, the BSC can also be utilised as a decision-making tool regarding the actions taken to correct deficiencies and advance the organisation.

This study discusses the results of empirical studies related to BSC implementation in various private hospitals by collecting existing literature.

\section{Research Method}

The researcher employed a systematic search strategy to identify the keywords "Balanced Scorecard" AND "Hospital" in 5 databases (Pubmed, Taylor\&Francis Online, Wiley, Springer, and Emerald). The five databases were screened from the title, the essence, to the entire paper. The researcher also checked whether the journals were Scopus-indexed or not. Furthermore, there were three journals being reviewed.

\section{Results}

The journals identified from the screening stage amounted to 2,396 journals. However, only three journals matched this study's inclusion and exclusion criteria. The first journal was from Ohio Summa Hospital, the second journal was from Barberton Citizen Hospital, and the third journal was from several private hospitals in Taiwan. Those three journals explained the impact of implementing the BSC in terms of financial and nonfinancial aspects.

Based on the study results, three journals were identified as suitable to the study objectives. Those journals were collected and screened to determine whether they had similar titles. The screening results indicated a relatively small number of journals, perhaps due to three reasons. First, the authors had difficulty obtaining the information on these topics since the studies discussing the details of BSC results on financial and nonfinancial aspects in health facilities had not been published. Second, the inclusion criteria for the selection of this study focused solely on research findings from private health facilities rather than results from public health facilities. Third, the journals had to be published as Scopus indexed journals. 


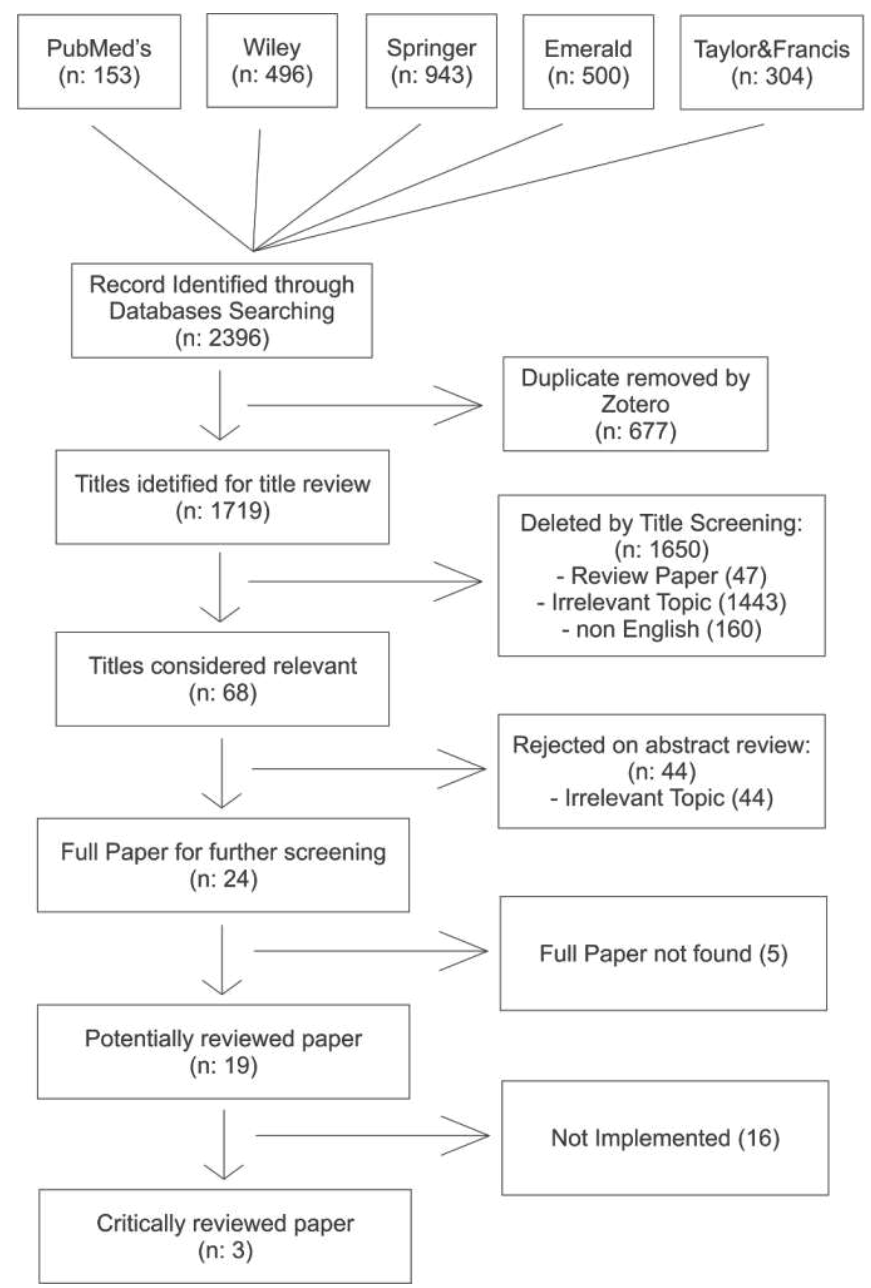

Fig. 1. PRISMA Protocol

Table 1. Selected Journals For Analysis

\begin{tabular}{llcc}
\hline No & \multicolumn{1}{c}{ Title } & Year Published & \multicolumn{1}{c}{ Author } \\
\hline 1 & Balanced Scorecard at Summa Health System & 2005 & $\begin{array}{c}\text { Heather Smith and Il-woon } \\
\text { Kim }\end{array}$ \\
2 & $\begin{array}{l}\text { Implementation of the Balanced Scorecard at } \\
\text { Barberton Citizen Hospital }\end{array}$ & 2008 & Josey Chuck and Il-woon \\
3 & $\begin{array}{l}\text { Performance improvement after implementing } \\
\text { the Balanced Scorecard: A large hospital's } \\
\text { experience in Taiwan }\end{array}$ & 2008 & $\begin{array}{c}\text { Wen-Cheng Chang, Yu-Chi } \\
\text { Tung, Chun-Hsiung Huang \& } \\
\text { Ming-Chin Yang }\end{array}$ \\
\hline
\end{tabular}


The first and third studies defined BSC as an assessment of performance goals based on the organisation's vision. This vision included finance, customer, internal business processes, and learning and growth. On the other hand, the second study described the BSC as five dimensions of long-term performance goals: people, service, quality, finance, and growth.

\section{Discussion}

Hospital is one of the healthcare organisations that also requires an organisation's performance description to perceive how the goals and objectives can be successfully achieved in accordance with its vision and mission[3]. The Balanced Scorecard (BSC) becomes one of the most widely used methods to describe organisational performance. The word "balanced" indicates that the organisation's performance, including the financial and non-financial, short-term and long-term, and internal and external aspects, is measured in a balanced manner[4]. On the other hand, the scorecard is a card used to record a person's performance score and compare it with the actual performance results. Therefore, the balanced scorecard (BSC) is an essential strategic management tool that can help organisations measure their performance and determine policies or strategies to achieve organisational goals. Since the 1990s, healthcare organisations have faced enormous challenges[5]. Healthcare organisations remain under pressure due to increased customer expectations, fierce competition, and pressure from policymakers[6].

According to Porporato et al. (2017), hospitals would obtain strategic benefit by implementing the BSC in accordance with the appropriate performance measurement indicators[7]. However, the BSC implementation in the healthcare sector has become more complex[8]. The healthcare sector differs from other organisations since it requires a balance between cost-efficiency, quality, and customer service[9]. Implementing the BSC also demands a significant change in organisational culture, leadership style, and beliefs[10]. Rabbani et al. (2011) asserted that the success of BSC implementation is determined by several factors, including participatory culture, leadership support, financial and non-financial incentives, and the integration of BSC policies into the organisations' resources and routine operational activities[11].

BSC is a performance achievement technique based on the organisation's internal capabilities, known as the Resources Based Theory[12]-[14]. BSC has four perspectives: finance, customers, internal business, and learning and growth. The financial perspective assesses the organisation's economic performance, efficiency, and effectiveness. The customer perspective includes five dimensions: physical evidence, reliability, responsiveness, assurance, and empathy. On the other hand, the internal business perspective has three dimensions: facility management, human resources (HR), and process. Lastly, the learning and growth perspective has two dimensions: ability and motivation.

Among the three reviewed journals, it could be concluded that there were financial and non-financial benefits in the BSC implementation. In terms of the financial aspect, there was an improvement in both income and cost-efficiency. This achievement was in line with the BSC theory, stating that the BSC implementation could improve financial performance by reducing the company's costs or expenses and increasing the company's source of income. In the non-financial aspect, there was also an improvement in customer satisfaction, productivity, and service quality.

In 2005, Heather Smith and Kim Il Woon from Summa Hospital, Ohio, reviewed the advantages and disadvantages of implementing BSC in the local health facilities. The results demonstrated an average increase in sales of $2 \%$ per month in the financial aspect. Besides, the non-financial results also revealed an increase in the quality audit results of food services. All four components of the audit conducted exceeded the target of $94 \%$. The overall customer satisfaction index reached $75.7 \%$, exceeding the target of $73.7 \%$. It could be identified that the BSC implementation provided a positive impact on hospital performance[15]. 
In 2008, Josey Chuck and Kim Il Woon conducted research at Barberton Citizens Hospital. In the financial aspect, they revealed that the average gross profit reached $6.8 \%$ with the target of $4.5 \%$, while the cost-toincome ratio amounted to $12 \%$ with the target of $13.4 \%$. In addition, there were several improvements in the non-financial aspects, i.e., employee satisfaction reached 3.2 points with the target of 3.1 points; the service quality met Gallup's standards; and, patient visits reached 49,794 people with the target of 13,200 people. This study also indicated the positive impact of the BSC implementation in the hospital[16].

In 2008, Wen-Cheng Chang, Yu-Chi Tung, Chun-Hsiung Huang, and Ming-Chin Yang conducted research in several private hospitals in Taiwan. Financially, the income increased from NT\$14.07 million to NT\$17.894 million. Meanwhile, in the non-financial aspect, the study results indicated increased patient satisfaction from $89.07 \%$ to $91.9 \%$. The number of treatments for poor and disabled patients increased from 82,350 to 97,658 patients. Internal research projects increased from 46 projects to 61 projects. The waiting time for ED patients was less than 3 hours, from $47.8 \%$ to $82.5 \%$. In Taiwan, hospitals' performance analysis using the BSC became an effective and efficient tool if it was carried out attentively, sustainably, and consistently to improve medical care management and cost control[17].

Not all of the three journals discussed conveyed the limitations of the study. Only two journals explained their limitations, i.e., a journal by Heather Smith and Kim Il-woon and a journal by Josey Chuck and Kim Ilwoon in 2008. Both studies were merely conducted in one private academic hospital since the researchers suggested that some other private hospitals in the country were comparable to the hospital studied[16].

Chang, et al. (2008) recommended that the findings of previous studies should be enriched with the existing literature and empirical evidence about the benefits of BSC implementation in the healthcare industry[17]. It also provided experiences for several countries as references for expanding the BSC implementation in hospital administration.

The recommendations provided in each study stated that, to implement BSC in a hospital setting, it is compulsory to ensure a participatory culture, clear institutional mandates, appropriate leadership support, proper reward systems, and awareness of the BSC benefits. BSC could improve the performance of each aspect, ranging from internal processes, quality of service facilities, patient services, safety and satisfaction, and the financial aspects.

\section{Conclusion}

The three journals suggest that the BSC implementation in the hospitals can improve the hospital's financial and non-financial performances. The BSC implementation in hospitals can provide clear direction in determining policies, managing resources and routine activities, and building systems in each hospital unit. The BSC can be applied in private and public hospitals as performance and guidelines measures in operational policies.

In connection with the analysed journals in this paper, there are three most likely reasons, i.e., first, many private hospitals did not publish the results of the BSC implementation; second, this study was limited only to private hospitals; third, the studies analysed had to be published as Scopus indexed journals.

The scope for further research can investigate why the BSC adoption in private hospitals is not yet widely available in academic journals. 


\section{References}

[1] A. Tyagi and P. Singh, "Hospital performance management: A multi-criteria decision-making approach," International Journal of Healthcare Management, vol. 12, no. 4, pp. 286-291, Oct. 2019, doi: 10.1080/20479700.2017.1337606.

[2] G. Ravish, "Current Trends in Performance Management: A Study of Healthcare Industry,” 2018, doi: 10.13140/RG.2.2.11498.16321.

[3] F. El-Jardali, S. Saleh, N. Ataya, and D. Jamal, "Design, implementation and scaling up of the balanced scorecard for hospitals in Lebanon: policy coherence and application lessons for low and middle income countries," Health Policy, vol. 103, no. 2-3, pp. 305-314, Dec. 2011, doi: 10.1016/j.healthpol.2011.05.006.

[4] L. Chang, "The NHS performance assessment framework as a balanced scorecard approach: Limitations and implications," Intl Jnl Public Sec Management, vol. 20, no. 2, pp. 101-117, Mar. 2007, doi: 10.1108/09513550710731472.

[5] J. R. Griffith, “Championship Management for Healthcare Organizations," Journal of Healthcare Management, 2000.

[6] C. Chow-Chua and M. Goh, "Framework for evaluating performance and quality improvement in hospitals," Managing Service Quality: An International Journal, vol. 12, no. 1, pp. 54-66, Jan. 2002, doi: 10.1108/09604520210415399.

[7] M. Porporato, P. Tsasis, and L. M. Marin Vinuesa, "Do hospital balanced scorecard measures reflect cause-effect relationships?," International Journal of Productivity \& Performance Management, vol. 66, no. 3, pp. 338-361, Apr. 2017, doi: 10.1108/IJPPM02-2015-0029.

[8] B. Gurd and T. Gao, "Lives in the balance: an analysis of the balanced scorecard (BSC) in healthcare organizations," Int J Productivity \& Perf Mgmt, vol. 57, no. 1, pp. 6-21, Dec. 2007, doi: 10.1108/17410400810841209.

[9] S. Noorein Inamdar, "Examining the Scope of Multibusiness Health Care Firms: Implications for Strategy and Financial Performance," Health Services Research, vol. 42, no. 4, pp. 1691-1717, Aug. 2007.

[10] L. Trong Tuan, "From unbalanced to balanced: performance measures in a Vietnamese hospital," Leadership in Health Services, vol. 25, no. 4, pp. 288-305, Jan. 2012, doi: 10.1108/17511871211268937.

[11] F. Rabbani et al., "Understanding the context of balanced scorecard implementation: a hospital-based case study in Pakistan," Implement Sci, vol. 6, p. 31, Mar. 2011, doi: 10.1186/1748-5908-6-31.

[12] M. A. Huselid and B. E. Becker, "Bridging Micro and Macro Domains: Workforce Differentiation and Strategic Human Resource Management," Journal of Management, vol. 37, no. 2, pp. 421-428, Mar. 2011, doi: 10.1177/0149206310373400.

[13] A. J. Nyberg, T. P. Moliterno, D. Hale, and D. P. Lepak, "Resource-Based Perspectives on Unit-Level Human Capital: A Review and Integration," Journal of Management, vol. 40, no. 1, pp. 316-346, Jan. 2014, doi: 10.1177/0149206312458703.

[14] E. Mollick, "People and process, suits and innovators: the role of individuals in firm performance," Strat. Mgmt. J., vol. 33, no. 9, pp. 1001-1015, Sep. 2012, doi: 10.1002/smj.1958.

[15] H. Smith and Il-Woon Kim, "Balanced scorecard at Summa health system," Journal of Corporate Accounting \& Finance (Wiley), vol. 16, no. 5, pp. 65-72, Aug. 2005.

[16] C. Josey and Il-woon Kim, "Implementation of the balanced scorecard at Barberton citizens hospital," Journal of Corporate Accounting \& Finance (Wiley), vol. 19, no. 3, pp. 57-63, Apr. 2008.

[17] W.-C. Chang, Y.-C. Tung, C.-H. Huang, and M.-C. Yang, "Performance improvement after implementing the Balanced Scorecard: A large hospital's experience in Taiwan,” Total Quality Management \& Business Excellence, vol. 19, no. 12, pp. 1257-1258, Dec. 2008, doi: 10.1080/14783360802637050. 